\title{
PLASMA OXIDATION OF PRINTED POLYSILOXANE LAYERS
}

\author{
${ }^{1}$ Július VIDA, ${ }^{2}$ Petr DZIK, ${ }^{1}$ Tomáš HOMOLA \\ ${ }^{1}$ Department of Physical Electronics, Faculty of Science, Masaryk University, Brno, Czech Republic, EU, \\ jvida@mail.muni.cz \\ ${ }^{2}$ Faculty of Chemistry, Brno University of Technology, Brno, Czech Republic, EU
}

https://doi.org/10.37904/nanocon.2021.4339

\begin{abstract}
Organosilica binders are a promising way to interconnect various nanoparticles in printed coatings for photovoltaic cells and other applications. Post-deposition treatment of printed nanoparticle films with organosilica binders is required to remove the organic moieties and thus achieve the optimal optoelectronic properties of the resulting film. As a result, the polysiloxane binder is converted to almost fully amorphous silica and this process is called mineralization. Atmospheric pressure plasma operating in open air has proven to be the most promising method, as the operating temperature can be kept below $70^{\circ} \mathrm{C}$ and the overall treatment time required is in order of minutes. These are significant advantages compared to alternative approaches like thermal sintering, where temperatures required are around $450^{\circ} \mathrm{C}$, or chemical or UV light treatment, where the treatment times extend into the order of hours. To better understand the underlying chemistry in the interaction of the ambient air plasma and the organosilica binder we performed an X-ray photoelectron spectroscopy (XPS) study on the plasma-treated films of silica binder, regularly used with titania nanoparticles. The detailed analysis of core-level spectra of $\mathrm{C} 1 \mathrm{~s}, \mathrm{O} 1 \mathrm{~s}$ and $\mathrm{Si} 2 \mathrm{p}$ were used to observe the removal of methyl groups from the film and gradual transformation into amorphous $\mathrm{SiO}_{2}$. The scanning electron microscope revealed significant patterning of the surface by interaction with plasma after exposures longer than 16 seconds.
\end{abstract}

Keywords: Nanoparticle binder, organosilica, plasma mineralization, DCSBD, atmospheric pressure plasma

\section{INTRODUCTION}

Sol-gel processes are widely used to prepare various silica gels for different applications including protective hydrophobic coatings [1]. Recently a process involving methyltriethoxysilane (MTEOS) precursor was developed and used to prepare a matrix in which titania nanoparticles were dispersed to obtain porous and flexible photocatalytically active coating [2]. The organosilica matrix acted as a binder interconnecting the nanoparticles. This has substituted the connections between nanoparticles that form during traditional hightemperature sintering and are necessary for desired properties of the film. It has been shown that these new coatings can be used as photoanodes in photovoltaic devices such as perovskite solar cells, which is the most interesting application of the coating so far [4].

As-deposited coatings without any curing, however, don't display satisfactory performance. The methyl groups in the organosilica binder hinder the electrical properties of the films and cause poor wettability if any subsequent overprinting is desired for more complicated devices. Three approaches for post-printing curing were compared: thermal sintering, UV light treatment, and air plasma treatment [6]. It was shown that all three methods cause minerallization of the binder resulting in fully insoluble and stable coating with improved mechanical properties of the film. Out of the three, the plasma approach is extremely attractive as the treatment times necessary can be reduced to one minute, the temperature can be kept below $70{ }^{\circ} \mathrm{C}$ providing 
compatibility with the temperature-sensitive flexible substrates, and the process is readily compatible with rollto-roll processing for preparing large area coatings.

The mechanism of minerallization of the organosilica binder is believed to involve the cleavage of methyl groups bonded to silicon and transformation into amorphous $\mathrm{SiO}_{x}$. The energetic nitrogen and oxygen species in plasma, specifically oxygen radicals, react with $\mathrm{Si}-\mathrm{CH}_{3}$ groups on the surface resulting in surface active sites [8]. We chose to study in the detail the chemical changes happening on the surface of polysiloxane coating. Up to now, all the studies reported the effect of curing on coatings of binder together with the nanoparticles. Elimination of the nanoparticles and analysing the polysiloxane coating by itself can give more detailed information about the minerallization process.

\section{EXPERIMENTAL PROCEDURE}

The preparation of recently developed organosilica binder, a hybrid silica sol based on MTEOS [2] was adopted without modification. The binder was diluted with isobutanol in ratio 1:20. The mixture was spin-coated onto a crystalline silicon wafer at 800 RPM for $10 \mathrm{~s}$ and then 3000 RPM for $30 \mathrm{~s}$.

Plasma was generated in ambient air by diffuse coplanar surface barrier discharge (DCSBD) - a dielectric barrier discharge with a coplanar arrangement of electrodes; commercialized by Roplass s.r.o. (Czech Republic) [3]. DCSBD generates plasma of high uniformity and power density up to $100 \mathrm{~W} / \mathrm{cm}^{3}$, while maintaining temperature below $70{ }^{\circ} \mathrm{C}$. The plasma region of the DCSBD unit was around $0.3 \mathrm{~mm}$ thick. To ensure a good contact of the sample surface with the plasma region the sample holder was distanced from the ceramics of the DCSBD unit by $0.3 \mathrm{~mm}$ of Kapton tape. The exposure time of the treated sample surface was varied from $0 \mathrm{~s}$ to $128 \mathrm{~s}$.

The surface chemistry of the films was determined from X-ray photoelectron spectra (XPS) obtained by AXIS Supra spectrometer from Kratos Analytical Ltd. (United Kingdom). The instrument uses Al Ka spectral line (1486.6 eV photon energy) and an electron flood gun was utilized for charge compensation. The acquisition of narrow regions of the spectrum was performed with the pass energy $20 \mathrm{eV}$. For analysis of the spectra CasaXPS software was used. The spectra were calibrated to $\mathrm{C}-\mathrm{C} / \mathrm{C}-\mathrm{H}$ peak of $\mathrm{C} 1 \mathrm{~s}$ at $285 \mathrm{eV}$ binding energy.

Mira3 scanning electron microscope (SEM) from Tescan (Czech Republic) was employed for the analysis of the morphology of the coatings and the effect of plasma. Prior to analysis the films were coated with $10 \mathrm{~nm}$ of $\mathrm{Au} / \mathrm{Pd}$ conductive film to reduce the charging of the surface by incident electrons. The images were captured at with $2000 \mathrm{x}$ and $5000 \mathrm{x}$ magnification, $10 \mathrm{kV}$ accelerating voltage and at a working distance of $10 \mathrm{~mm}$.

\section{RESULTS AND DISCUSSION}

We used X-ray photoelectron spectroscopy (XPS) was used to analyze the changes in the surface chemistry on the surface of the polysiloxane coatings. In Table 1 the atomic concentrations of the elements detected on the surface are shown. Immediately after the exposure to plasma for just one second, we observe a significant increase in the oxygen concentration from the original $45 \%$ to $61 \%$ and a decrease of the carbon concentration from $32 \%$ to $13 \%$. A small amount of nitrogen was introduced to the surface (below $1 \%$ ) during the ambient air plasma treatment. Prolonged plasma exposure did not cause any further changes in the surface elemental composition. After 128 seconds the surface contained $62 \%$ of oxygen and $12 \%$ of carbon. The silicon content remained relatively stable during the plasma treatment, $24 \%$ on the original coating and $26 \%$ after 128 seconds of treatment. The removal of carbon and replacement by oxygen agrees with the results of previous studies [4]. 
Table 1 Atomic concentrations on the surface of polysiloxane film before and after plasma exposure, obtained from XPS

\begin{tabular}{|c|c|c|c|c|}
\hline Treatment time & Silicon [\%] & Oxygen [\%] & Carbon [\%] & Nitrogen [\%] \\
\hline $\mathbf{0 ~ s}$ & $23.7 \pm 0.1$ & $44.8 \pm 0.6$ & $31.5 \pm 0.6$ & 0 \\
\hline $\mathbf{1 ~ s}$ & $25.5 \pm 0.6$ & $61 \pm 1$ & $13.0 \pm 0.7$ & $0.51 \pm 0.01$ \\
\hline $\mathbf{8 ~ s}$ & $25.4 \pm 0.1$ & $62 \pm 1$ & $12 \pm 1$ & $0.6 \pm 0.3$ \\
\hline $\mathbf{1 6} \mathbf{s}$ & $24.9 \pm 0.2$ & $62.8 \pm 0.1$ & $11.6 \pm 0.1$ & $0.8 \pm 0.2$ \\
\hline $\mathbf{3 2} \mathbf{s}$ & $25.2 \pm 0.1$ & $62.1 \pm 0.7$ & $12.0 \pm 0.3$ & $0.7 \pm 0.5$ \\
\hline $\mathbf{6 4} \mathbf{S}$ & $25.7 \pm 0.1$ & $61.6 \pm 0.1$ & $12.1 \pm 0.4$ & $0.7 \pm 0.2$ \\
\hline $\mathbf{1 2 8} \mathbf{s}$ & $25.8 \pm 0.1$ & $62.1 \pm 0.2$ & $11.7 \pm 0.1$ & $0.4 \pm 0.1$ \\
\hline
\end{tabular}

The high-resolution core-level XPS spectra of the films are shown in Figure 1. Figure 1a compares the C 1s region of the untreated and plasma-treated film. The main peak at low binding energy is made up of two components corresponding to $\mathrm{Si}-\mathrm{CH}_{3}$ environment and the carbon in $\mathrm{C}-\mathrm{C} / \mathrm{C}-\mathrm{H}$ hydrocarbon from some organic contamination on the surface at binding energies $284.5 \mathrm{eV}$ and $285.0 \mathrm{eV}$, respectively. Furthermore, we observe contribution from $\mathrm{C}-\mathrm{OH}$ at $286.5 \mathrm{eV}$ and after plasma treatment contributions from $\mathrm{O}-\mathrm{C}=\mathrm{O}$ at $288 \mathrm{eV}$ appear. This is a result of oxidation by plasma. We also observe significant shift of the main peak from $284.5 \mathrm{eV}$ to $285.0 \mathrm{eV}$ over the increasing plasma treatment times. This is a direct observation of the removal of methyl groups that are bound to silicon in the binder.

Figure 1b shows the high-resolution $\mathrm{O}$ 1s XPS spectrum. The reference sample of untreated displayed a single peak at $532.4 \mathrm{eV}$ corresponding to a oxygen in the $\mathrm{CH}_{3}-\mathrm{Si}-\mathrm{O}_{3 / 2}[2,5]$. After the exposure to ambient air plasma for just one second a shift towards higher binding energies is observed. This shift is believed to be caused by a transformation of the surface of the coating into amorphous silica under the influence of oxygen species in plasma. After exposure to plasma the position of the peak is $532.9 \mathrm{eV}$ corresponding to the oxygen in $\mathrm{SiO}_{2}$. The $\mathrm{Si} 2 \mathrm{p}$ region of the XPS spectra is shown in Figure 1c. The contribution from the silicon atoms in $\mathrm{CH}_{3}-\mathrm{Si}-\mathrm{O}_{3 / 2}$ and $\mathrm{SiO}_{2}$ are located at $102.5 \mathrm{eV}$ and $103.7 \mathrm{eV}$ [7]. Since the difference in binding energy is larger than in the $O 1 \mathrm{~s}$ spectrum, the changes in the chemistry can be observed more easily. After the plasma treatment we can see a shift from the original position $102.5 \mathrm{eV}$ to higher binding energies. After short treatments the resulting peak is broader, indicating a combination of contribution from both environments. With prolonged treatment time the peak gets narrower and moves to higher binding energies, suggesting a complete transition to amorphous silica and an increased depth in the film where the plasma has an effect. This ultrafast minerallization of the polysiloxane film offers the same result as a much slower minerallization under exposure to UV light presented in previous studies [2].
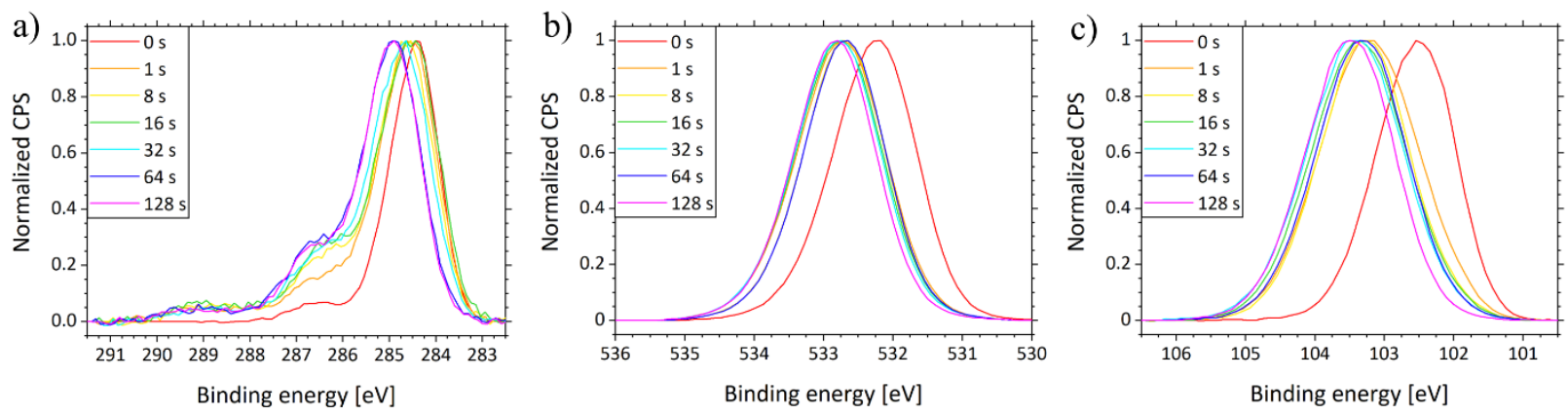

Figure 1 Comparison of a) $\mathrm{C} 1 \mathrm{~s}$, b) $\mathrm{O} 1 \mathrm{~s}$ and c) Si $2 p$ high-resolution core-level X-ray photoelectron spectra of untreated and plasma treated films 
Figure 2 shows SEM images of untreated and plasma-treated coatings. The $16 \mathrm{~s}$ plasma-treated sample in Figure $\mathbf{2 c}$ begins to show patterning of the surface because of the interactions with the plasma. This patterning becomes more pronounced as the plasma exposure is prolonged. Figure $2 f$ shows the sample treated for $128 \mathrm{~s}$. The SEM image shows very sharp features of hills and valleys presumably caused by the etching of some areas on the surface of the film by plasma.
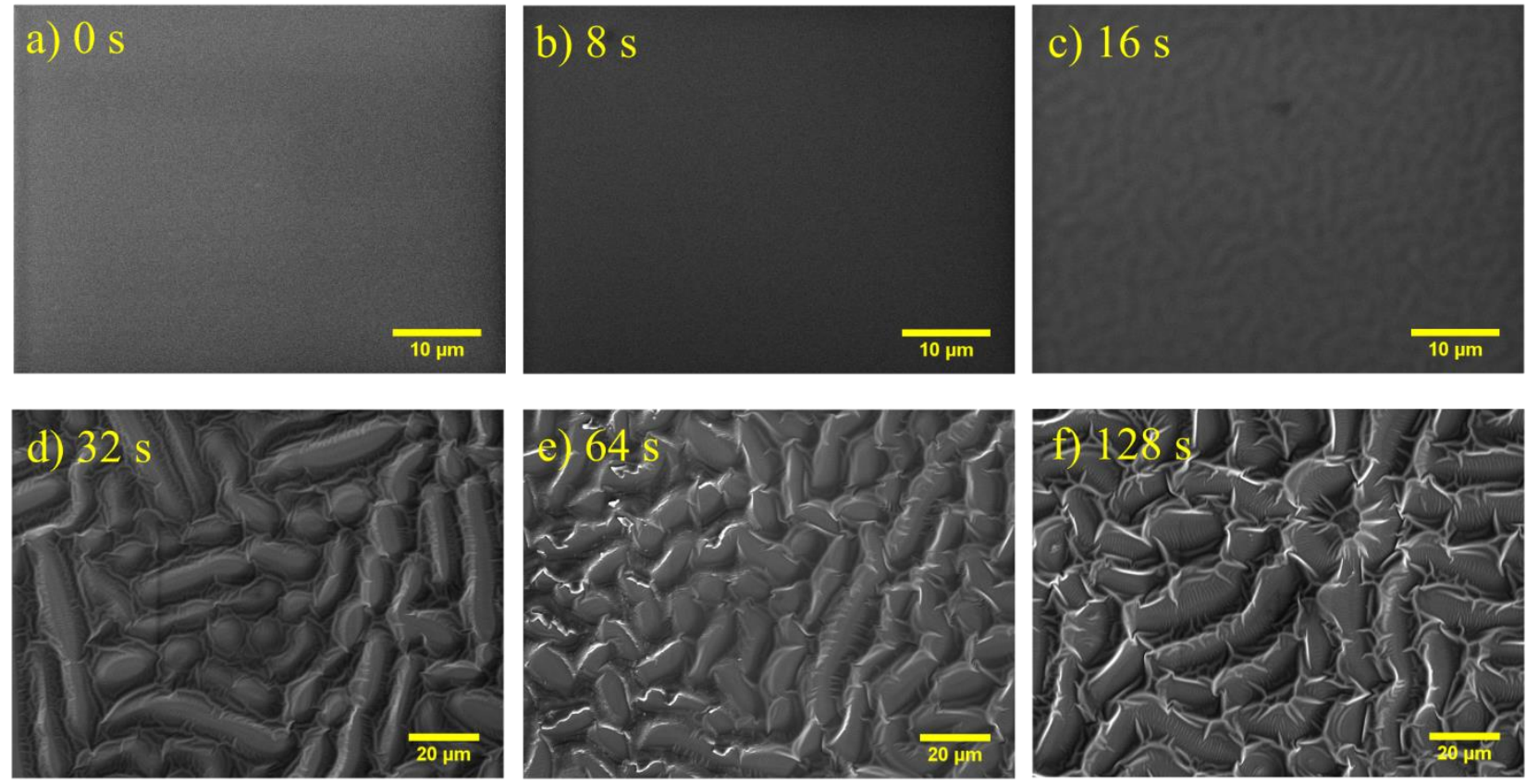

Figure 2 Images from scanning electron microscope of a) untreated and b)-f) plasma treated for 8-128 s. The a) untreated, b) $8 \mathrm{~s}$ and c) $16 \mathrm{~s}$ treated samples are magnified 5000 times. The d) $32 \mathrm{~s}$, e) $64 \mathrm{~s}$ and f) $128 \mathrm{~s}$ treated samples are shown magnified 2000 times.

\section{CONCLUSION}

In this paper we report a detailed XPS study of an ultra-fast minerallization of polysiloxane coating by atmospheric pressure ambient air plasma. Energetic species from plasma react with the $\mathrm{Si}-\mathrm{CH}_{3}$ bonds on the surface transforming them into amorphous silica. The whole surface is converted after just one second of treatment. Prolonged exposure to plasma causes the minerallization to occur deeper in the film. It also causes etching resulting in patterning of the surface.

\section{ACKNOWLEDGEMENTS}

This research has been supported by Czech Science Foundation project 19-14770Y and projects LM2018097 and LM2018110 funded by Ministry of Education, Youth and Sports of Czech Republic.

\section{REFERENCES}

[1] DARMAWAN, A., HANDAYANI, D.L., SAPUTRA, R. E. Hydrophobic silica films derived from methyltriethoxysilane (MTES): Effect of pH and calcination temperature. Applied Physics A. [online]. 2021, vol. 127, no. 9, pp. 1-8. Available from: https://doi.org/10.1007/S00339-021-04794-1.

[2] GRÉGORI, D., BENCHENAA, I., CHAPUT, F., THÉRIAS, S., GARDETTE, J. L., LÉONARD, D., GUILLARD, S., PAROLA, S. Mechanically stable and photocatalytically active $\mathrm{TiO}_{2} / \mathrm{SiO}_{2}$ hybrid films on flexible organic substrates. Journal of Materials Chemistry A. [online]. 2014, vol. 2, no. 47, pp. 20096-20104, Available from: https://doi.org/10.1039/c4ta03826f. 
[3] ČERNÁK, M., ČERNÁKOVÁ, L., HUDEC, I., KOVÁČIK, D., ZAHORANOVÁ, A.. Diffuse coplanar surface barrier discharge and its applications for in-line processing of low-added-value materials. EPJ Applied Physics. [online]. 2009, vol. 47, no. 2, Available from: https://doi.org/10.1051/epjap/2009131.

[4] HOMOLA, T., POSPISIL, J., SHEKARGOFTAR, M., SVOBODA, T., HVOJNIK, M., GEMEINER, P., WEITER, M., DZIK, P.. Perovskite Solar Cells with Low-Cost $\mathrm{TiO}_{2}$ Mesoporous Photoanodes Prepared by Rapid LowTemperature $\left(70{ }^{\circ} \mathrm{C}\right)$ Plasma Processing. ACS Applied Energy Materials. [online]. 2020, vol. 3, no. 12, pp. 12009-12018. Available from: https://doi.org/10.1021/acsaem.0c02144.

[5] O'HARE, L. A., HYNES, A., ALEXANDER, M. R.. A methodology for curve-fitting of the XPS Si 2p core level from thin siloxane coatings. Surface and Interface Analysis. [online]. 2007, vol. 39, no. 12-13, pp. 926-936. Available from: https://doi.org/10.1002/sia.2634.

[6] DZIK, P., VESELÝ, M., PACHOVSKÁ, M., NEUMANN-SPALLART, M., BURŠíKOVÁ, V., HOMOLA, T.. The influence of curing methods on the physico-chemical properties of printed mesoporous titania patterns reinforced by methylsilica binder. Catalysis Today. [online]. 2018, vol. 313, pp. 26-32. Available from: https://doi.org/10.1016/J.CATTOD.2018.01.012.

[7] O'HARE, L. A., PARBHOO, B., LEADLEY, S. R.. Development of a methodology for XPS curve-fitting of the Si $2 p$ core level of siloxane materials. Surface and Interface Analysis. [online]. 2004, vol. 36, no. 10, pp. 1427-1434. Available from: https://doi.org/10.1002/sia.1917.

[8] BAKLANOV, M. R., MARNEFFE, J. F., SHAMIRYAN, D., URBANOWICZ, A. M., SHI, H., RAKHIMOVA, T. V., HUANG, H., HO, P.S.. Plasma processing of low-k dielectrics. Journal of Applied Physics. [online]. 2013, vol. 113, no. 4, p. 041101. Available from: https://doi.org/10.1063/1.4765297. 